\title{
Analysis of Noise Figure of GaN HEMT at High Frequency Range for Microwave Applications
}

\author{
Shakti Tripathi \\ School of ICT \\ Gautam Buddha University \\ Greater Noida, India
}

\author{
Gurjit Kaur, PhD \\ School of ICT \\ Gautam Buddha University \\ Greater Noida, India
}

\begin{abstract}
Microwave and Millimeter Wave Integrated Circuits have experienced a tremendous growth over the last five decades. Circuits have become smaller, highly integrated, lower in cost, and have found extensive applications in radar, electronic warfare and the commercial field. MMIC approach is being used extensively these days where silicon technology is failing with the increase demand in low cost, less power consuming, more compact electronic devices. One of the very convincing MMIC approach has been discussed here is GaN HEMT. The small signal and noise analysis has been done and the results obtained which could act as a driving factor in many microwave applications.
\end{abstract}

\section{Keywords}

GaN HEMT, MMIC, s-parameters, NF.

\section{INTRODUCTION}

1.1.Aluminium-gallium-nitride/gallium-nitride( $\mathrm{AlGaN} / \mathrm{GaN})$ High Electron Mobility Transistors, HEMTs are one of the most reported state of the art GaN-based semiconductor devices [1]. In recent years, GaN based HEMTs are pursued extensively for applications in high power microwave amplifiers operating at high temperature [2].In this paper, the small signal analysis as well as noise analysis has been done and the results obtained. The value of the noise figure was found to be very less between the frequency range $2-5 \mathrm{GHz}$ and 20-50 GHz. For designing wide dynamic range microwave front-end system, the lower value of noise figure makes GaN HEMT very attractive as a new technology source. In the previous work by Syed S. Islam et al. [3], a significant increase in operating frequency and efficiency of class-E power amplifier, was obtained with GaN HEMT as the active device. There was no noise analysis of GaN HEMT in this work. Other previous works reported minimum microwave noise figures of $0.53 \mathrm{~dB}$ at $8 \mathrm{GHz}(100-\mathrm{GHz}$ device, $8 \mathrm{~V})$ and $0.4 \mathrm{~dB}$ at $5 \mathrm{GHz}(58-\mathrm{GHz}$ device, $1 \mathrm{~V})$ for AlGaN/GaN HEMTs [4], [5] respectively. The present work shows the noise figure of $0.537 \mathrm{~dB}$ at a low bias voltage of 1.8 $\mathrm{V}$ obtained at a frequency of $50 \mathrm{GHz}$.

\subsection{Small Signal Network Analysis}

As it is pointed out in the technique name, small signal network analysis is device characterization technique where the measurements are done under small signal power conditions. Under small signal analysis it is considered signals are small enough not to drive the device into saturation and thus have only linear affect on the device [6].

\section{GaN HEMT SCHEMATIC MODEL}

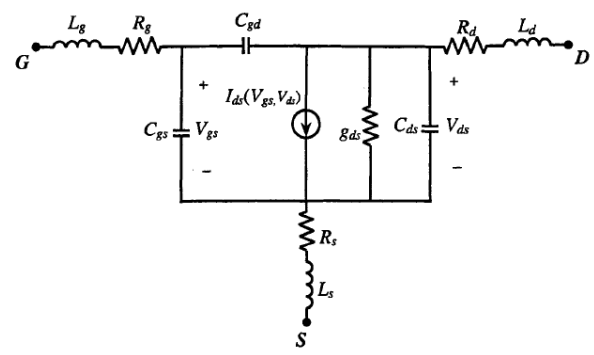

Figure 1: Equivalent circuit model of GaN HEMT [3]

The equivalent circuit model is used for the noise analysis as well as for s-parameters extraction at a bias voltage of $1.8 \mathrm{~V}$. The rest of the model parameters are obtained from reported experimental data that are listed in Table 1.

The above circuit diagram was implemented in Cadence Virtuoso and simulation had been done.

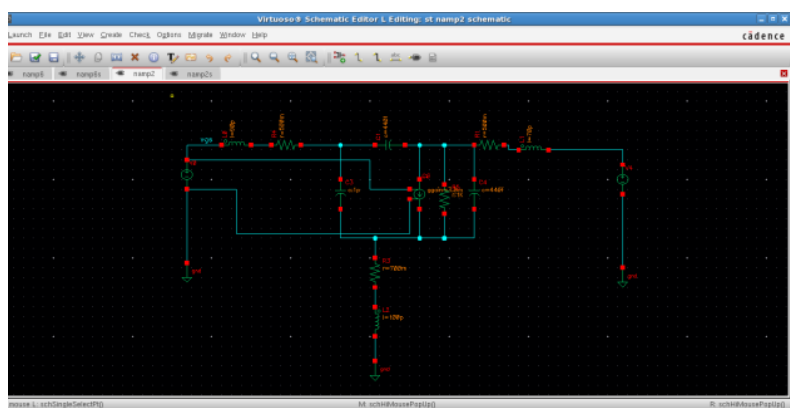

Figure 2: Schematic Diagram of GaN HEMT in CADENCE-VIRTUOSO

The values used for the simulation of the above schematic are given below:- 
Table 1. Design parameters used in the schematic [3]

\begin{tabular}{|l|l|l|l|l|l|l|l|l|}
\hline $\begin{array}{l}\mathbf{R} \\
\mathbf{g}\end{array}$ & $\mathbf{L g}$ & $\mathbf{R s}$ & $\mathbf{L s}$ & $\mathbf{C d s}$ & $\begin{array}{l}\mathbf{R} \\
\mathbf{d}\end{array}$ & $\mathbf{L d}$ & $\mathbf{g m}$ & $\begin{array}{l}\text { Vd } \\
\mathbf{c}\end{array}$ \\
\hline .5 & $.09 \mathrm{n}$ & .7 & $.1 \mathrm{n}$ & $.44 \mathrm{pF} /$ & .5 & $.07 \mathrm{n}$ & $\begin{array}{l}3.8 \\
\mathrm{~m}\end{array}$ & $\begin{array}{l}1.8 \\
\mathrm{\Omega}\end{array}$ \\
$\mathrm{H}$ & $\Omega$ & $\mathrm{H}$ & $\mathrm{mm}$ & $\Omega$ & $\mathrm{H}$ & $\begin{array}{l}\mathrm{Mh} \\
\text { os }\end{array}$ & \\
\hline
\end{tabular}

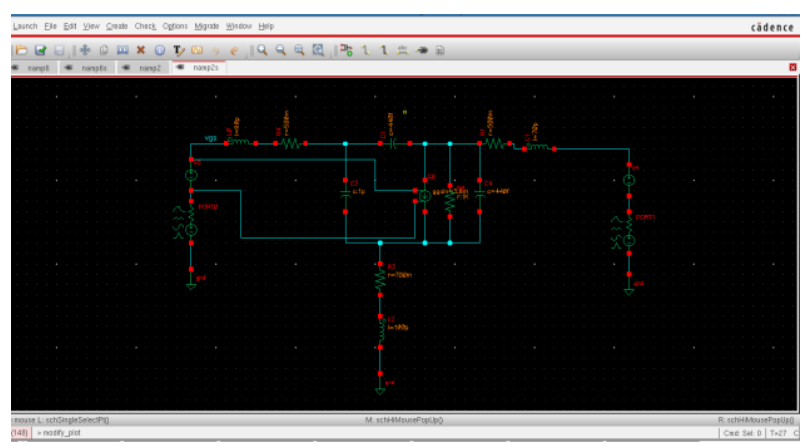

Figure 3: Schematic of GaN HEMT using input and output ports

The fundamental goal of s-parameters these measurements are presenting the effects of RF energy flow through device [8]. For any two-port device, the scattering matrix consists of four $s$ parameters $\left(S_{11}, S_{12}, S_{21}, S_{22}\right)$, fully describing device performance. For a two port network $s$ parameters has the following descriptions:

$\mathrm{S}_{11}$ is the input port voltage reflection coefficient

$\mathrm{S}_{12}$ is the reverse voltage gain

$\mathrm{S}_{21}$ is the forward voltage gain

$\mathrm{S}_{22}$ is the output port voltage reflection coefficient.

The schematic of GaN HEMT using the input and output ports was used to determine the scattering parameters. Scattering parameters (s parameters) are all what small signal network analysis is about.

\section{RESULT ANALYSIS}

The s-parameters were calculated at different frequencies within the range of $45 \mathrm{MHz}-50 \mathrm{GHz}$.

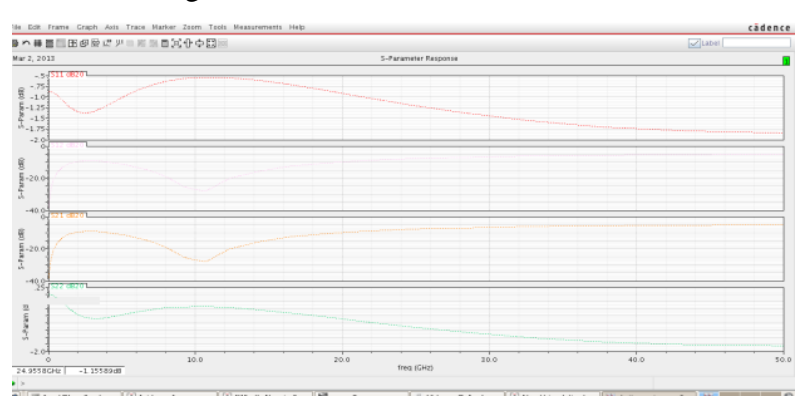

Figure: $4 S_{11}, S_{12}, S_{21} \& S_{22}$ parameters

The figure 4 shows the values of scattering parameters in the frequency range of $45 \mathrm{MHz}-50 \mathrm{GHz}$. The plots of $S_{11}$ and $S_{22}$ show that the input and output port reflection coefficients are maximum at frequency approximately equal to $10 \mathrm{GHz}$. The plots of $S_{12}$ and $S_{21}$ show that the forward and reverse voltage gains converge at the frequency approximately equal to 10 GHz.
For good s-parameter data the following conditions must be satisfied:-

- $\quad$ For passive reciprocal parts, $\mathrm{S}_{12}$ must equal $\mathrm{S}_{21}$.

- For passive parts, $\mathrm{S}_{21}$ and $\mathrm{S}_{12}$ can't be greater than $0 \mathrm{~dB}$.

The values of $S_{11}, S_{12}, S_{21}, S_{22}$ at different frequencies is given below:-

Table 2. Different values of $S_{11}$ at different frequencies

\begin{tabular}{|c|c|}
\hline Frequency $(\mathbf{H z})$ & $\mathbf{S}_{\mathbf{1 1}}$ (magnitude) \\
\hline $47.7099 \mathrm{M}$ & .9998 \\
\hline $3.19656 \mathrm{G}$ & .9070 \\
\hline $10.1622 \mathrm{G}$ & .9516 \\
\hline $39.9000 \mathrm{G}$ & .8222 \\
\hline $50.0000 \mathrm{G}$ & .8125 \\
\hline
\end{tabular}

Table 3. Different values of $S_{12}$ at different frequencies

\begin{tabular}{|c|c|}
\hline Frequency $(\mathbf{H z})$ & $\mathbf{S}_{\mathbf{1 2}}$ (magnitude) \\
\hline $51.7759 \mathrm{M}$ & .0136 \\
\hline $2.9000 \mathrm{G}$ & .3502 \\
\hline $10.6800 \mathrm{G}$ & .0383 \\
\hline $29.1325 \mathrm{G}$ & .4591 \\
\hline $50.0000 \mathrm{G}$ & .5531 \\
\hline
\end{tabular}

Table 4. Different values of $S_{21}$ at different frequencies

\begin{tabular}{|c|c|}
\hline Frequency(Hz) & $\mathbf{S}_{\mathbf{2 1}}$ (magnitude) \\
\hline $68.54 \mathrm{M}$ & .0180 \\
\hline $2.74 \mathrm{G}$ & .3500 \\
\hline $10.68 \mathrm{G}$ & .0380 \\
\hline $24.39 \mathrm{G}$ & .4000 \\
\hline $50.00 \mathrm{G}$ & .5530 \\
\hline
\end{tabular}

Table 5. Different values of $S_{22}$ at different frequencies

\begin{tabular}{|c|c|}
\hline Frequency(Hz) & $\mathbf{S}_{\mathbf{2 2}}$ (magnitude) \\
\hline $46.64 \mathrm{M}$ & .9048 \\
\hline $2.62 \mathrm{G}$ & .8541 \\
\hline $10.22 \mathrm{G}$ & .8193 \\
\hline $27.29 \mathrm{G}$ & .8193 \\
\hline $50.00 \mathrm{G}$ & .8093 \\
\hline
\end{tabular}

The values shown in the table satisfies the condition for good $\mathrm{s}$ parameters i.e. the reverse voltage gain and the forward voltage gain are equal. For passive parts they are also not greater than $0 \mathrm{~dB}$. After the s-parameters were calculated, 
noise figure was plotted using the same biasing conditions as for the s-parameters.

The noise figure was also plotted and is given below:-

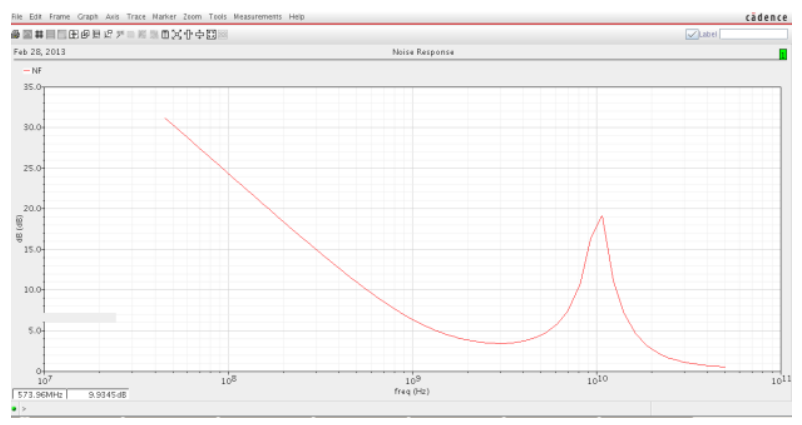

Figure 5: Noise Figure plot

The values of noise figure at different frequencies are given below:-

Table 6. Values of Noise Figure at different frequencies

\begin{tabular}{|c|c|}
\hline Frequency(Hz) & Noise Figure(dB) \\
\hline $45.399 \mathrm{M}$ & 31.17 \\
\hline $5.429 \mathrm{G}$ & 4.970 \\
\hline $11.330 \mathrm{G}$ & 15.86 \\
\hline $21.095 \mathrm{G}$ & 2.410 \\
\hline $50.000 \mathrm{G}$ & .5370 \\
\hline
\end{tabular}

The performance of most RF and microwave communications, radar, and remote sensing systems is critical to noise because noise ultimately determines the threshold for the minimum signal that can be reliably detected by a receiver. In either case the noise level of a system sets the lower limit on the strength of a signal that can be detected in the presence of the noise. Noise should be kept minimum of the device in consideration as noise can be passed into a microwave system from external sources or generated within the system itself.

Here we see in Table 6 that the value of the noise figure has decreased as we have increased the frequency, the less value of noise figure shows that the system is more sensitive.

The signal to noise ratio degradation is remarkably low in the frequency range of $2-5 \mathrm{GHz}$ and $20-50 \mathrm{GHz}$.

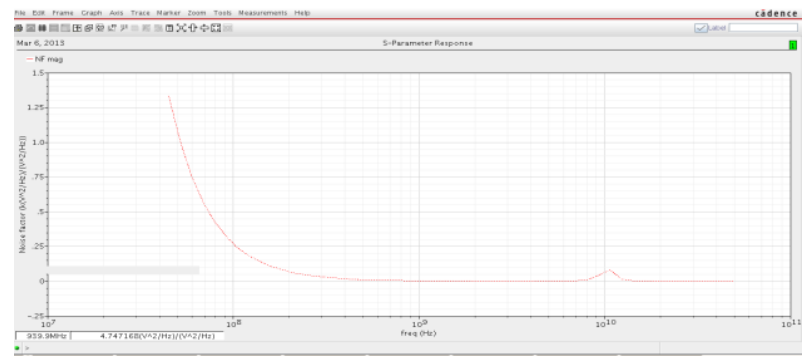

Figure 6 Noise Factor plot
Table 7. Values of Noise Factor at different frequencies

\begin{tabular}{|c|c|}
\hline Frequency $(\mathrm{Hz})$ & Noise Factor \\
\hline $45.21 \mathrm{M}$ & $1.323 \mathrm{k}$ \\
\hline $103.58 \mathrm{M}$ & 253.78 \\
\hline $1.05 \mathrm{G}$ & 4.330 \\
\hline $10.80 \mathrm{G}$ & 76.74 \\
\hline $30.02 \mathrm{G}$ & 1.300 \\
\hline
\end{tabular}

The noise factor is close to 1 at frequency range of $2.3 \mathrm{GHz}$ to $5.7 \mathrm{GHz}$. This means that the network adds minimum noise at these frequencies. The noise is occurring dominantly due to the source of noise and noise introduced by the network is extremely low.

\section{CONCLUSION AND FUTURE WORK}

The values of s-parameters show that the impedance matching of the network is done successfully. The GaN HEMT exhibits fine operation in the frequency range of $1 \mathrm{GHz}$ to $50 \mathrm{GHz}$. The values of noise figure and noise factor suggest that the transistor is highly immune to noise in the selected frequency range. In this work, the low noise capability of the $\mathrm{GaN}$ HEMT device technology is revealed. Determination of the precise intrinsic noise sources for $\mathrm{AlGaN} / \mathrm{GaN}$ HEMTs is the emphasis of this work and it was found that the noise is occurring in the system dominantly due to the source and at a high frequency of $50 \mathrm{GHz}$, the noise figure was $0.537 \mathrm{~dB}$. After the noise analysis, an accurate noise equivalent-circuit model can be developed which could help in prediction of performance and study of noise mechanisms within the device.

\section{REFERENCES}

[1] M. A. Khan, "High Electron Mobility Transistor Based on a GaN-AlxGa1-xN Heterojunction," Applied Physics Letters, vol. 63 No. 9, pp. 1214-1215, Aug., 1993.

[2] M.Higashiwaki, T.Mimura, and T.Matsui, "30-nm-Gate AlGaN/GaN Heterostructure Field-Effect Transistors with a Current-Gain Cutoff Frequency of $181 \mathrm{GHz}$," Jpn J Appl Phys Part 2, vol. 45, no.42-45, pp. L1111-L1113, 2006

[3] Syed S. Islam, A.F.M. Anwar, Spice Model of AlGaN/GaN HEMTs And Simulation of VCO And Power Amplifier", International Journal of High Speed Electronics and Systems, vol. 14, no. 3, pp-853-859, 2004.

[4] W. Lu, J. Yang, M. A. Khan, and I. Adesida, "AlGaN/GaN HEMTs on $\mathrm{SiC}$ with over $100 \mathrm{GHz}$ f and low microwave noise," IEEE Trans. Electron Devices, vol. 48, pp. 581-585, Mar. 2001.

[5] T. Hussain, A. Kurdoghlian, P. Hashimoto, W. S. Wong, M. Wetzel, J.S. Moon, L. McCray, and M. Micovic, "GaN HFET's with excellent low noise performance at lower power levels through the use of thin $\mathrm{AlGaN}$ Schottky barrier layer," in Int. Electron Devices Meeting Tech. Dig., 2001, pp. 581-584. 
[6] http://www.microwaves101.com/encyclopedia/FETs.cfm -The On-line Microwave Engineering Encyclopedia.

[7] Syed S. Islam, A.F.M. Anwar, Spice Model of AlGaN/GaN HEMTs And Simulation of VCO And Power Amplifier", International Journal of High Speed Electronics and Systems, vol. 14, no. 3, pp-853-859, 2004.

[8] http://www.microwaves101.com/encyclopedia/sparamete rs.cfm- The On-line Microwave Engineering Encyclopedia.
[9] William Sutton, Mike Wojtowicz, and Aaron Oki, "A Cool, Sub-0.2 dB Noise Figure GaN HEMT Power Amplifier With 2-Watt Output Power", IEEE Journal Of Solid-State Circuits,vol. 44, no. 10, Oct., 2009.

[10] Sungjae Lee, Kevin J. Webb,Vinayak Tilak, and Lester F. Eastman, "Intrinsic Noise Equivalent-Circuit Parameters for AlGaN/GaN HEMTs", IEEE Transactions On Microwave Theory And Techniques, Vol. 51, No. 5, May 2003. 